\title{
Prospective Prevention of Neonatal Hyperammonaemia in Argininosuccinic Acidura by Arginine Therapy
}

\author{
S. M. DONN ${ }^{1}$ and J. G. THOENE \\ Department of Pediatrics and Communicable Diseases, Section of Newborn Services, \\ and Section of Metabolic Disease, University of Michigan Hospitals, Ann Arbor, Michigan, USA
}

\begin{abstract}
Argininosuccinic aciduria, due to deficiency of argininosuccinic acid lyase, is generally associated with severe neonatal hyperammonaemia and its neurological sequelae. The cases of two siblings with this autosomal recessive disorder are presented. Both infants were preterm and delivered by Caesarean section for maternal pre-eclampsia. The first infant was not diagnosed until after the development of severe hyperammonaemia and, despite adequate treatment with haemodialysis and arginine infusion, remained comatose for a prolonged period. At 20 months she has profound developmental delays and intellectual impairment. The second infant, whose diagnosis was made antenatally by amniotic fluid analysis, was treated with arginine infusion beginning at $32 \mathrm{~h}$ of life and never developed hyperammonaemia. We conclude that early recognition and prompt institution of arginine therapy is an effective regimen for the prevention of neonatal hyperammonaemia in argininosuccinic aciduria.
\end{abstract}

Argininosuccinic aciduria (ASA) (McKusick 20790) is a rare inherited disorder of the urea cycle characterized by a deficiency of the enzyme argininosuccinic acid lyase (AL) (EC4.3.2.1) and the presence of large quantities of argininosuccinic acid and ammonia in the urine and body fluids. The incidence of this autosomal recessive disease is estimated at 1 per 70000 live births in the United States (Batshaw and Brusilow, 1980). The neonatal-onset form is associated with the development of hyperammonaemia and its clinical manifestations in the first few days of life, usually after the institution of protein feedings. Respiratory distress, vomiting, hypotonia, convulsions and coma may ensue, and most of the affected infants have died in the neonatal period (Batshaw and Brusilow, 1980). Spongy degeneration, focal necrosis, and the presence of Alzheimer type II glia, pathognomonic of hyperammonaemic injury, have been demonstrated upon neuropathologic examination of the brains of non-survivors (Batshaw et al., 1982). Maintenance of normal plasma ammonia concentration is the major goal of neonatal treatment, accomplished by preventing excessive ammonia production or facilitating its removal.

The ability of arginine therapy to prevent neonatal hyperammonaemia in ASA is illustrated by two siblings with ASA. The first infant was not diagnosed until significant hyperammonaemia had already developed. The second infant was diagnosed in utero by amniotic fluid analysis and received prompt arginine treatment which prevented the development of hyperammonaemia.

\section{METHODS}

Plasma ammonia concentrations were determined by the clinical pathology laboratory of the University of Michigan, using a modification of the method of Van

\footnotetext{
${ }^{1}$ Address for correspondence: Box 007, L3023 Women's Hospital,
} Ann Arbor, MI 48109-0010, USA. Telephone: (313) 763-4109.
Anken and Schiphorst (1974) and an automated clinical analyser (DuPont ACA III). Plasma amino acids and urea cycle intermediates were measured by a Beckman $118 \mathrm{CL}$ analyser. Argininosuccinic lyase activity was determined by the method of Fleisher et al. (1983) utilizing ${ }^{14} \mathrm{C}$-citrulline/ $/{ }^{3} \mathrm{H}$-leucine incorporation into protein.

\section{Patient 1}

The first infant, a $2100 \mathrm{~g}$ female, was delivered at 35 weeks gestation by emergency Caesarean section for maternal pre-eclampsia. The Apgar scores were 8 and 10 at 1 and $5 \mathrm{~min}$, respectively and the infant appeared well until the fourth day of life when she became lethargic, fed poorly, and displayed a diminished suck and moro response. She rapidly deteriorated, developing apnoea, hypotonia, and eventually coma, requiring intubation and mechanical ventilation. Prior to transfer, her plasma ammonia concentration was $941 \mu \mathrm{moll}^{-1}$. Upon admission, she was without spontaneous activity and totally unresponsive to stimuli. Plasma ammonia concentration was $1172 \mu \mathrm{mol} 1^{-1}$. She underwent $2 \mathrm{~h}$ of haemodialysis which successfully lowered plasma ammonia to $78 \mu \mathrm{mol}^{-1}$ but was not associated with neurologic improvement. A diagnosis of ASA was made based on elevated plasma concentrations of argininosuccinate $\left(4.5 \mathrm{mmol} \mathrm{l}^{-1}\right)$ and citrulline $\left(0.33 \mathrm{mmol}^{-1}\right)$, and marked argininosuccinic aciduria and moderate orotic aciduria $\left(2.8 \mu \mathrm{mol} \mathrm{mg}\right.$ creatinine $^{-1}$; normal $<0.03 \mu \mathrm{mol} \mathrm{mg}$ creatinine $\left.{ }^{-1}\right)$. A return of the plasma ammonia concentration to $496 \mu \mathrm{moll}^{-1}$ necessitated the institution of intravenous $10 \%$ arginine- $\mathrm{HCl}$ therapy which was infused at $4 \mathrm{mmol} \mathrm{kg}^{-1} \mathrm{day}^{-1}$ (Figure 1). This was followed by a decrease in plasma ammonia concentration to $58 \mu \mathrm{moll}^{-1}$ over the next $24 \mathrm{~h}$ and associated with the return of superficial and deep tendon reflexes and spontaneous respirations. For the remainder of her hospital course, her plasma ammonia concentrations remained below $32 \mu \mathrm{moll}^{-1}$ and upon institution of oral feedings she was treated with a 


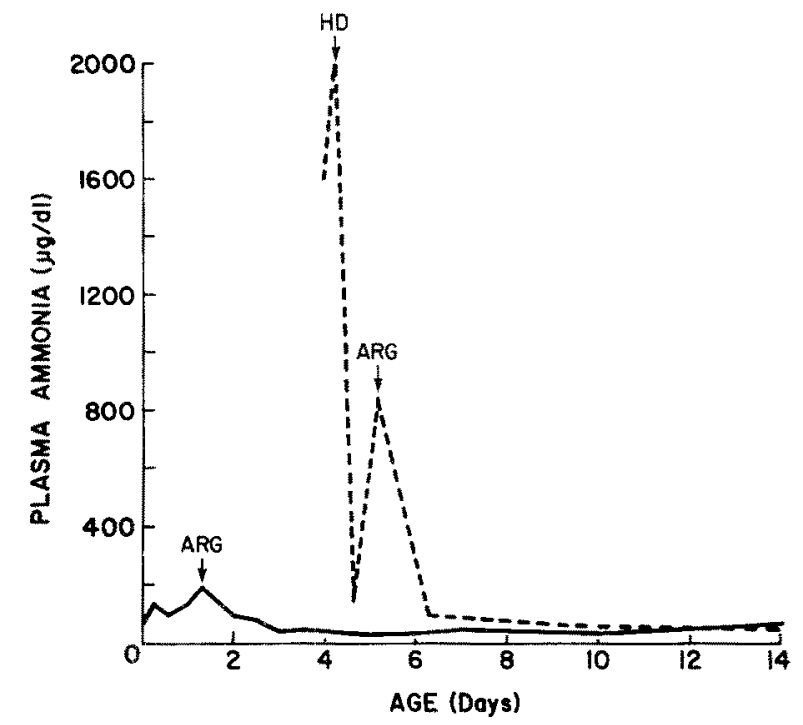

Figure 1 Clinical courses of plasma ammonia concentrations during the first 14 days of life for two siblings with argininosuccinic aciduria. Broken line represents Patient 1, solid line represents Patient $2 . \mathrm{ARG}=$ arginine- $\mathrm{HCl}$ infusion, $\mathrm{HD}=$ haemodialysis

mixture of arginine (free base) and ornithine acetate ( $2 \mathrm{mmol} \mathrm{kg}^{-1} \mathrm{day}^{-1}$ of each).

\section{Patient 2}

A subsequent pregnancy was achieved by the same couple. Amniocentesis was performed in the $23 \mathrm{rd}$ week of the pregnancy and a diagnosis of ASA was made, based on the detection of argininosuccinic acid in the amniotic fluid $\left(43 \mu \mathrm{mol}^{-1}\right)$ and deficient lyase activity in amniocytes; ${ }^{14} \mathrm{C}$-citrulline $/{ }^{3} \mathrm{H}$-leucine incorporation into protein demonstrated a control value of 0.107 and a patient value of 0.012 using the method of Fleisher et al. (1983). This pregnancy was also complicated by preeclampsia; spontaneous rupture of the membranes at 32 weeks prompted maternal transfer to the University of Michigan where a repeat Caesarean section was performed. The second infant, a $1780 \mathrm{~g}$ male, had Apgar scores of 7 and 8 at 1 and $5 \mathrm{~min}$, respectively. He developed mild hyaline membrane disease requiring $24 \mathrm{~h}$ of assisted ventilation for hypercapnia. ASA was confirmed by plasma and urinary amino acid analysis and by assay of AL activity in umbilical cord fibroblasts. His plasma ammonia concentration, $33 \mu \mathrm{moll}^{-1}$ at birth, rose to a maximum of $115 \mu \mathrm{mol}^{-1}$ at $32 \mathrm{~h}$ of age, at which time an intravenous arginine infusion was begun $\left(4 \mathrm{mmol} \mathrm{kg} \mathrm{kgy}^{-1}\right.$ ). After $48 \mathrm{~h}$ of arginine therapy, plasma ammonia declined to $29 \mu \mathrm{moll} \mathrm{l}^{-1}$ and thereafter never exceeded $65 \mu \mathrm{mol} 1^{-1}$, even with dietary protein intake as high as $3.0 \mathrm{~g} \mathrm{~kg}^{-1} \mathrm{day}^{-1}$. He was successfully switched from intravenous arginine to oral arginine and ornithine acetate $\left(2 \mathrm{mmol} \mathrm{kg}^{-1} \mathrm{day}^{-1}\right.$ of each) with continued successful control of the plasma ammonia concentration. At no time during the neonatal period did he display abnormal neurological signs or symptoms.

\section{DISCUSSION}

Defects of the urea cycle preclude de novo synthesis of arginine and result in its becoming an essential amino acid in patients with these defects. In addition to supplying enough arginine for protein synthesis, arginine therapy permits patients with ASA to perform an "abbreviated" urea cycle commencing with ornithine and terminating with the excretion of a large amount of ASA which contains both molecules of nitrogen which would normally be excreted as urea if the cycle were intact (Brusilow and Batshaw, 1979; Batshaw and Brusilow, 1980; Batshaw et al., 1982).

In AL deficiency, administered arginine is converted rapidly to ornithine and subsequently to ASA by the intact enzymes of the urea cycle (Batshaw et al., 1981). The efficacy of arginine therapy is conditional upon early diagnosis and treatment. In the first patient, the development of profound and life-threatening hyperammonaemia required immediate intervention. We (Donn et al., 1979) and others (Wiegand et al., 1980) have demonstrated the safety and efficacy of haemodialysis for the treatment of hyperammonaemia in the newborn using the readily accessible umbilical artery and vein. As shown in the figure, the plasma ammonia concentration in the first infant fell to normal values after only $2 \mathrm{~h}$ of haemodialysis; however, the effect was transient and arginine therapy was required to maintain normal plasma ammonia concentration. In utero diagnosis (Goodman et al., 1973, Collins et al., 1980; Fleisher et al., 1983) in the second infant permitted institution of treatment prior to the development of significant hyperammonaemia. This obviated the need for either haemodialysis or peritoneal dialysis and their inherent risks and complications.

Table 1 displays the effect of arginine treatment on the plasma concentrations of urea cycle intermediates in the two patients. Post-treatment determinations were made after the patients had received $24 \mathrm{~h}$ of a continuous infusion of arginine at a dose of $4 \mathrm{mmol} \mathrm{kg} \mathrm{may}^{-1}$. It is interesting to note that in both cases the plasma ASA concentration equilibrated at about the same level $\left(1910-1850 \mu \mathrm{mol}^{-1}\right)$ with treatment at the same dose, but these values were approached from opposite directions. Homeostasis under these circumstances depends upon supplying adequate arginine for effective

Table 1 The effect of arginine treatment on the concentration of urea cycle intermediates in plasma $\left(\mu_{\mathrm{moll}}{ }^{-1}\right)$

\begin{tabular}{lrrrc}
\hline & Citrulline & ASA & Arg & Orn \\
\hline Patient 1 & & & & \\
$\quad$ pretreatment & 327 & 4506 & 46 & ND \\
post-treatment & 847 & 1910 & 360 & 211 \\
Patient 2 & & & & \\
$\quad$ pretreatment & 51 & 544 & 44 & 43 \\
$\quad$ post-treatment & 310 & 1850 & 184 & 47 \\
Normal range & $<30$ & ND & $54 \pm 17$ & $91 \pm 25$ \\
\hline
\end{tabular}

ND, not detectable

ASA, argininosuccinic acid

Arg, arginine

Orn, ornithine 
ammonia removal and also upon adequate renal function to dispose of the ASA thus generated.

Intravenous arginine therapy in both infants was associated only with a mild persistent metabolic acidosis which responded to supplemental sodium bicarbonate therapy. This may have resulted from the hydrochloride salt of arginine; when both infants were switched to the oral preparation of arginine as the free 'base' and ornithine acetate, the metabolic acidosis resolved without the need for alkali therapy.

Treatment of inborn errors of the urea cycle has advanced greatly in the past decade with the advent of alternative methods of waste nitrogen disposal. Early diagnosis and treatment of arginosuccinate lyase deficiency with arginine appears to be a highly effective management of potentially lethal hyperammonaemia in the newborn period. Msall et al. (1984) recently demonstrated the association between prolonged neonatal hyperammonaemic coma with brain damage and impaired intellectual function in children with urea cycle enzymopathies. Although the long-term prognosis for individuals with arginosuccinate lyase deficiency successfully managed in the neonatal period is unknown, the avoidance of neonatal hyperammonaemia and its catastrophic complications appears achievable.

The authors thank Dr Mark L. Batshaw and Dr Saul W. Brusilow for supplying the arginine and ornithine supplements for Patient 1; Dr Dan Verberg for performing the amniocentesis and maternal referral for Patient 2; Dr Lynn Fleisher for performing the arginosuccinate lyase determinations; Rosemary Lemons for amino acid analysis and excellent technical assistance; and Julie Tate for preparation of the manuscript. This paper was supported in part by the March of Dimes Medical Service Grant No. C376 and the Michigan Department of Mental Health Genetic Screening Program.

$M S$ received 3.5 .84

Accepted for publication 18.7.84

\section{References}

Batshaw, M. L. and Brusilow, S. W. Treatment of hyperammonemic coma caused by inborn errors of urea synthesis. J. Pediatr. 97 (1980) 893-900

Batshaw, M. L., Brusilow, S. W., Waber, L., Blom, W., Brubakk, A. M., Burton, B. K., Cann, H. M., Kerr, D., Mamunes, P., Matalon, R., Myerberg, D. and Schafer, I. A. Treatment of inborn errors of urea synthesis. Activation of alternative pathways of waste nitrogen synthesis and excretion. N. Engl. J. Med. 306 (1982) 1387-1392

Batshaw, M. L., Thomas, G. H. and Brusilow, S. W. New approaches to the diagnosis and treatment of inborn errors of urea synthesis. Pediatrics 68 (1981) 290-297

Brusilow, S. W. and Batshaw, M. L. Arginine therapy for argininosuccinic deficiency. Lancet 1 (1979) 134-136

Collins, F. S., Summer, G. K., Schwartz, R. P. and Parke, J. C., Jr. Neonatal argininosuccinic aciduria-survival after early diagnosis and dietary management. J. Pediatr. 96 (1980) $429-431$

Donn, S. M., Swartz, R. D. and Thoene, J. G. Comparison of exchange transfusion, peritoneal dialysis, and hemodialysis for the treatment of hyperammonemia in an anuric newborn infant. J. Pediatr. 95 (1979) 67-70

Fleisher, L. D., Harris, C. J. and Mitchell, D. A. Citrullinemia: prenatal diagnosis of an affected fetus. Am. J. Hum. Genet. 35 (1983) 85-90

Goodman, S. I., Mace, J. W. and Turner, B. Antenatal diagnosis of argininosuccinic aciduria. Clin. Genet. 4 (1973) 236-239

Msall, M., Batshaw, M. L., Suss, R., Brusilow, S. W. and Mellits, E. D. Neurologic outcome in children with inborn errors of urea synthesis. Outcome of urea-cycle enzymopathy, N. Engl. J. Med. 310 (1984) 1500-1550

Van Anken, H. C. and Schiphorst, M. E. A kinetic determination of ammonia in plasma. Clin. Chem. Acta 56 (1974) $151-157$

Wiegand, C., Thompson, T., Bock, G. H., Mathis, R. K., Kjellstrard, C. M. and Mauer, S. M. The management of lifethreatening hyperammonemia: a comparison of several therapeutic modalities. J. Pediatr. 96 (1980) 142-144 